\title{
MDMA ("Ecstasy") Abuse and High-Risk Sexual Behaviors Among 169 Gay and Bisexual Men
}

Robert L. Klitzman, M.D.

Harrison G. Pope, Jr., M.D.

James I. Hudson, M.D.

Objective: The authors explored the association between abuse of 3,4-methylenedioxymethamphetamine (MDMA, or "Ecstasy") and high-risk sexual behaviors among gay and bisexual men.

Method: An anonymous questionnaire was completed by 169 gay and bisexual men at three New York City dance clubs. The questionnaire covered demographic indices, use of MDMA and other drugs, and history of high-risk sexual behaviors.

Results: About one-third of the respondents reported MDMA use at least monthly. MDMA use was strongly and significantly associated with a history of recent unprotected anal intercourse. This association remained equally strong even after controlling for age, ethnicity, and all other forms of drug use, including alcohol.

Conclusions: MDMA abuse, and its strong association with highrisk sexual behaviors, appears to represent important unexplored public health problems among some gay or bisexual men.

(Am J Psychiatry 2000; 157:1162-1164)
$\mathrm{O}$ ver the last 20 years, abuse of 3,4-methylenedioxymethamphetamine (MDMA, or "Ecstasy") has increased sharply, especially at late-night dance clubs and at dance parties known as "raves" (1). This abuse represents a potential public health problem, since the drug may cause lasting neurotoxicity (2) and psychopathology (3). Yet no published studies, to our knowledge, have addressed the associations between MDMA abuse, sexual orientation, and high-risk sexual behaviors. These associations may be important, since MDMA may increase energy, sexual receptivity (4), and "warmth and openness"(5), which has led some to call it the "love drug"(1) or the "hug drug"(5). To provide preliminary data in this area, we surveyed gay and bisexual men recruited from dance clubs in New York City.

\section{Method}

We distributed an anonymous one-page self-report questionnaire to 180 men as they entered three predominantly gay New York City dance clubs on three successive Saturday nights. The questionnaire, available from Dr. Klitzman, covered age; self-reported sexual orientation; current frequency of MDMA use, other illicit drug use, and alcohol use; history of sexually transmitted diseases; HIV status (if known to the respondent); and frequency of insertive and receptive anal intercourse without a condom within the past year. The questionnaire was developed for the study and did not incorporate previously validated questions. The study was approved by the Columbia University Department of Psychiatry institutional review board.

\section{Results}

Since questionnaire respondents were asked to complete the questionnaire immediately upon receiving it, all of the 180 questionnaires that we distributed were collected. However, only 172 (96\%) of these were evaluable; two were filled out incoherently, and six others failed to specify the respondent's sexual activity or frequency of MDMA use. Submitted questionnaires that supplied at least these two items were considered evaluable. Of the 172 evaluable respondents, 119 (69\%) described themselves as gay, $50(29 \%)$ as bisexual, and three $(2 \%)$ as heterosexual men. We examined the 169 subjects who identified themselves as gay or bisexual. These men were a mean age of 24.2 years $(\mathrm{SD}=6.4$, range $=16-44$, median= 22); $95(56 \%)$ described themselves as white, $34(20 \%)$ as Latino, seven $(4 \%)$ as black, five (3\%) as Asian-Pacific Islanders, and $28(17 \%)$ as "other" or no answer. About one-third of these men reported at least monthly use of MDMA - a proportion greater than that for any other category of illicit drugs except marijuana, which only slightly exceeded MDMA in frequency (Table 1).

Of 155 respondents who answered the question about insertive anal intercourse, $11(7 \%)$ reported that they had engaged in this behavior "often" in the past year, 23 (15\%) engaged in it "sometimes," 37 (24\%) reported that they "rarely" engaged in the behavior, and $84(54 \%)$ reported that they "never" engaged in the behavior during the past year. For the 159 respondents who answered the receptive anal intercourse question, the corresponding figures were eight (5\%), 19 (12\%), 46 (29\%), and 86 (54\%). Of 152 respondents who answered the question regarding HIV status, $104(68 \%)$ reported that they had been tested; of these, four $(4 \%)$ reported that they were HIV positive, $82(79 \%)$ reported that they were HIV negative, and 18 (17\%) left the question blank. Of the 82 self-reported HIV-negative men, $36(44 \%)$ reported engaging in insertive or receptive anal intercourse within the last year, as compared to $29(60 \%)$ of the 48 who reported not having been HIV tested ( $\mathrm{p}=$ 0.051, Fisher's exact test, two-tailed).

We defined "high-risk sexual behavior" as any unprotected insertive or receptive anal intercourse in the past 
TABLE 1. Substances and Frequency of Use Reported by 169 Gay or Bisexual Men Surveyed at Three New York City Dance Clubs and Association With High-Risk Sexual Behavior ${ }^{\mathrm{a}}$

\begin{tabular}{|c|c|c|c|c|c|c|c|c|c|c|c|}
\hline \multirow[b]{3}{*}{ Substance } & \multicolumn{10}{|c|}{ Frequency of Use $^{b}$} & \multirow{3}{*}{$\begin{array}{l}\text { Association } \\
\text { With High- } \\
\text { Risk Sexual } \\
\text { Behavior }^{c}\end{array}$} \\
\hline & \multicolumn{2}{|c|}{$\begin{array}{l}\text { Four or More } \\
\text { Times/Week }\end{array}$} & \multicolumn{2}{|c|}{$\begin{array}{l}\text { One to Three } \\
\text { Times/Week }\end{array}$} & \multicolumn{2}{|c|}{$\begin{array}{l}\text { At Least Once/Month but } \\
\text { Less Than Once/Week }\end{array}$} & \multicolumn{2}{|c|}{$\begin{array}{l}\text { At Least Once/Year but } \\
\text { Less Than Once/Month }\end{array}$} & \multicolumn{2}{|c|}{$\begin{array}{l}\text { None in } \\
\text { Last Year }\end{array}$} & \\
\hline & $\mathrm{N}$ & $\%$ & $\mathrm{~N}$ & $\%$ & $\mathrm{~N}$ & $\%$ & $\mathrm{~N}$ & $\%$ & $\mathrm{~N}$ & $\%$ & \\
\hline MDMA & 11 & 7 & 20 & 12 & 26 & 15 & 31 & 18 & 81 & 48 & 0.02 \\
\hline Alcohol & 43 & 25 & 60 & 36 & 36 & 21 & 17 & 10 & 13 & 8 & 0.73 \\
\hline Marijuana & 19 & 11 & 23 & 14 & 21 & 12 & 38 & 22 & 68 & 40 & 0.35 \\
\hline Cocaine or "crack" & 2 & 1 & 5 & 3 & 20 & 12 & 27 & 16 & 115 & 68 & 0.26 \\
\hline Inhaled nitrites & 3 & 2 & 8 & 5 & 10 & 6 & 17 & 10 & 131 & 78 & 0.47 \\
\hline Hallucinogens & 5 & 3 & 2 & 1 & 5 & 3 & 30 & 18 & 126 & 75 & 0.18 \\
\hline Methamphetamine & 1 & 1 & 0 & 0 & 12 & 7 & 20 & 12 & 136 & 80 & 0.44 \\
\hline Other "uppers" & 2 & 1 & 7 & 4 & 9 & 5 & 15 & 9 & 136 & 80 & 0.06 \\
\hline Ketamine & 9 & 5 & 16 & 9 & 16 & 9 & 23 & 14 & 105 & 62 & 0.11 \\
\hline
\end{tabular}

a Total $\mathrm{N}$ for each drug category may not total 169 because of missing data.

b Only drugs used at least monthly by 10 or more of the subjects are listed within the table. Other reported substances used at least monthly were sedatives $(5 \%, \mathrm{~N}=9), \gamma$-hydroxybutyrate (“GHB”) $(4 \%, \mathrm{~N}=6)$, heroin and other opiates $(3 \%, \mathrm{~N}=5)$, and phencyclidine ( $2 \%$, $\mathrm{N}=4)$.

c Values represent $\mathrm{p}$ values resulting from two-tailed Fisher's exact tests.

year. Of 157 respondents who could be scored for presence or absence of high-risk sexual behavior, 90 (57\%) reported that they had engaged in this behavior in the past year. As shown in Table 1, of all the categories of drugs used at least monthly or more by 10 or more respondents, only MDMA was significantly associated with high-risk sexual behavior. To analyze this association further, we defined binary categories of "frequent MDMA use" for respondents reporting at least monthly MDMA use and "infrequent use or nonuse" for all others. We then assessed the association between high-risk sexual behavior and frequent MDMA use, first by computing the risk ratios and subsequently by examining odds ratios by means of a logistic regression analysis, both unadjusted and adjusted for the effects of age (under 20, 20-24, 25-29, over 30); ethnicity (Caucasian versus non-Caucasian); sexual orientation (gay versus bisexual); club attended; and frequency of alcohol use (less than once/week versus at least weekly) and other drug use (less than once/week versus at least weekly use of any illicit drug).

We found a strong association between frequent MDMA use and high-risk sexual behavior. The risk ratio for highrisk sexual behavior among frequent versus nonfrequent MDMA users was 1.37 (95\% confidence interval $[\mathrm{CI}]=1.10$ 1.70). In view of the $50 \%$ prevalence of high-risk sexual behavior even among nonfrequent MDMA users, this risk ratio reflects an alarming absolute increase in risk of $23 \%$ associated with frequent MDMA use. The unadjusted odds ratio was 2.77 (95\% CI=1.35-5.65) for high-risk sexual behavior and changed little when adjusted for other covariates $(2.87,95 \% \mathrm{CI}=1.20-6.84)$. It is of interest that neither frequent alcohol use nor frequent use of other drugs was significantly associated with high-risk sexual behavior (risk ratios of 1.03 [95\% CI=0.69-1.50] and 1.03 [95\% CI= 0.81-1.31], respectively), which suggests that the association between frequent MDMA use and high-risk sexual behavior was not attributable to the confounding effects of other drug use.

\section{Discussion}

In an anonymous questionnaire survey of 169 self-reported gay or bisexual men at three New York City dance clubs, we found strikingly high rates of MDMA use that exceeded rates for all other illicit drugs except marijuana. Moreover, MDMA use was strongly and significantly associated with high-risk sexual behaviors, and this association remained equally strong even after controlling for alcohol use, all other forms of illicit drug use, and various demographic measures.

The reasons for the association between MDMA use and high-risk sexual behaviors remain to be investigated. Although high-risk sexual behaviors have been linked to the use of other illicit drugs $(6,7)$, possibly as a result of "sensation seeking" (8) or altered judgment (6), the striking and seemingly independent association of high-risk sex with use of MDMA remains unexplained. It is possible that individuals who abuse MDMA harbor high premorbid tendencies for risk-taking or that subcultural influences from other MDMA users encourage higher levels of risky sexual behaviors. Alternatively, MDMA-induced intoxication, residual neurotoxicity (7), or psychopathology (6) may compromise users' judgments about the hazards of their sexual behavior.

Several limitations of this study should be considered. First, some club patrons did not stop to accept a questionnaire at the entrance, thus creating possible selection bias. Second, gay and bisexual men at New York City dance clubs cannot be assumed to be representative of gay and bisexual men in the United States as a whole. Third, since this was not an interview study, we were unable to validate formally the questionnaire responses or query subjects directly about the relationship between high-risk behavior and each of the substances used. Nevertheless, the findings of this pilot study suggest that frequent MDMA use and its association with high-risk sexual behaviors may represent largely unexplored public health problems among some gay or bisexual men. 
Received Feb. 16, 1999; revision received Aug. 2, 1999; accepted Oct. 18, 1999. From the HIV Center for Clinical and Behavioral Studies, New York State Psychiatric Institute/Columbia University Department of Psychiatry; the Biological Psychiatry Laboratory, McLean Hospital, Belmont, Mass.; the Department of Psychiatry, Harvard Medical School, Boston; and the Department of Biostatistics, Harvard School of Public Health, Boston. Address reprint requests to Dr. Klitz man, HIV Center for Clinical and Behavioral Studies, New York State Psychiatric Institute/Columbia University Department of Psychiatry, 1051 Riverside Dr., Unit 15, New York, NY 10032.

\section{References}

1. Randall J: Ecstasy-fueled "rave" parties become dances of death for English youths. JAMA 1992; 268:1505-1506

2. McCann UD, Szabo Z, Scheffel U, Dannals R, Ricaurte G: Positron emission tomographic evidence of toxic effect of
MDMA ("Ecstasy") on brain serotonin neurons in human beings. Lancet 1998; 352:1433-1437

3. McGuire PK, Cope H, Fahy T: Diversity of psychopathology associated with use of 3,4-methylenedioxymethamphetamine. Br J Psychiatry 1994; 165:391-395

4. Buffum J, Moser C: MDMA and human sexual function. J Psychoactive Drugs 1986; 18:355-359

5. Solowij N, Hall W, Lee N: Recreational MDMA use in Sydney: a profile of "Ecstasy" users and their experiences with the drug. Br J Addict 1992; 87:1161-1172

6. Leigh B, Stall R: Substance use and risky sexual behavior for exposure to HIV. Am Psychol 1993; 48:1035-1045

7. Mulry G, Kalichman S, Kelly J: Substance use and unsafe sex among gay men: global versus situational use of substances. J Sex Education and Therapy 1994; 20:175-184

8. Kalichman S, Heckman T, Kelly J: Sensation seeking as an explanation for the association between substance use and HIVrelated risky sexual behavior. Arch Sex Behav 1996; 25:141154 